\title{
Attitudes toward Finance: A Focus Group Study on Women in Italy
}

\author{
Elisa Bocchialini \\ Beatrice Ronchini \\ University of Parma \\ Department of Economics and Management \\ Parma, Italy
}

\begin{abstract}
In spite of the amount of research conducted on financial literacy, the literature offers little information about the role of attitude toward finance in financial achievement. This exploratory study aims to fill this knowledge gap by investigating the phenomenon of 'attitude toward finance', viewed as potentially connected to people's financial knowledge levels. The study focuses on a sample of 87 women aged between 19 and 65 years old in order to assess and compare their attitude to finance. Methodologically, this is a qualitative study based on focus group discussions. We find different 'attitude profiles' in our sample reflecting the complex interaction of affect with learning finance, cognitive competence, value, difficulty, and interest in finance. As might be expected, women with a specific educational or professional path in finance are found to have a more favourable attitude toward finance. Conversely, age appears to have no relationship with attitude toward finance. The implications of these findings for research and practice are discussed.
\end{abstract}

Keywords: financial literacy, attitudes toward finance, women, focus group

JEL Classification: A22; D14; J16.

\section{Introduction}

Despite a clear downward trend in educational and occupational segregation by gender, men and women continue to follow different directions in education and careers (Correll, 2001; OECD, 2011). Finance, like STEM, remains mainly male-dominated (Prescott and Bogg, 2011). In Italy, women are still vastly underrepresented in senior positions in the financial sector (World Economic Forum, 2010; Del Prete and Stefani, 2013) and among graduates in finance (Noè, 2012). Women tend to be considerably less financially literate than their male counterparts all over the world (AA.VV., 2014). In Italy, the phenomenon is more alarming as the average level of financial literacy of the population is in itself low in absolute terms (OECD, 2013b; Klapper et al., 2015), and the financial knowledge gender gap persists among the younger generation, while it has substantially disappeared in almost all OECD countries (OECD, 2014). All of these stylized facts feed the suspicion that Italian women have an uneasy relationship with 'finance', and the underlying hypothesis in this study is that the financial literacy gap and the discrepancy in the participation rates of women in finance may be largely a question of attitude. We investigate whether there is a collective female aversion to finance, what type of attitude toward finance women have and whether certain attitudes toward finance an be detrimental to their financial knowledge.

In recent years, increasing attention has been paid to the impact of the attitudinal variables on the financial literacy process (Atkinson et al., 2006; Johnson and Staten, 2010; OECD, 2013a; Bongini et al., 2013; OECD, 2014). However, this research area is in its infancy and lacks a clear theoretical framework, an unambiguous definition of attitude and shared measurement instruments. The construct of 'attitude toward finance', for example, which differs from both 'financial attitude' and 'financial aptitude' (Garder, 1975; Gauld and Hukins, 1980; Rao, 2010) has so far been a neglected variable in financial education studies. To the best of our knowledge, no study has as yet investigated the construct. Given this gap in knowledge, this study focuses on the 'attitude toward finance' construct, using a focus group format, which is a valuable research instrument to remedy the absence of substantial information (Stewart and Shamdasani, 1990; Krueger, 1994; Kitzinger, 1995). The focus of the study is finance, viewed as a discipline of study, as a daily practice for financial well-being and as a career choice. 
For our purpose, attitude toward finance reflects the durable mix of emotional response, beliefs and self-perceived competence of a person relating to finance ${ }^{1}$ (Di Martino and Zan, 2010). As an exploratory study, this focuses on a sample of 87 women in order to assess and compare their attitudes toward finance. Our target group is exclusively women, because a sample of the population homogeneous with respect to gender offers the unique opportunity to investigate the question of attitude by excluding any specific effect of gender diversity. Our aim is not to investigate the impact of gender, and the paper deals thus identifies women's attitudes towards finance and how they might differ among various socio-demographic groups. The main research questions are as follows: Do the different categories of women in the sample show a different 'attitude profile' toward finance? What factors influence women's attitudes to finance? What relevant ideas emerge from focus group discussions that will contribute to increasing the body of knowledge regarding women's attitude toward finance?

The paper has a threefold aim. First, we seek to provide some preliminary findings about this under-researched topic the 'attitude towards finance' - in order to contribute to the development of a theoretical base and suggest directions for further research. Second, we aim to gain a deeper understanding of what kind of variables influence the construct. Third, focus group results should identify a set of testable hypotheses for further investigation. The remainder of the paper is organized as follows. In Section 2, the existing literature on attitude to finance is examined. The main aspects of the methodological procedures are introduced in Section 3, where the socioeconomic characteristics of the sample, the model, and the methodology are presented. Section 4 presents the analysis and discussion of results. Finally, Section 5 summarises and concludes.

\section{Literature review}

There is a growing consensus among researchers in financial literacy that the construct 'attitude' deserves special attention. In addition to cognitive factors, affective factors play a crucial role in the financial literacy process (Atkinson et al., 2006; Johnson and Staten, 2010; OECD, 2013a; Bongini et al., 2013).The frameworkof the Programme for International Student Assessment(PISA) 2012 places 'attitude' as an integral part of the financial literacy construct, together with two other pillars: 'knowledge' and 'behaviour' (OECD, 2014).Recent empirical studies have been conducted on this theme by different sets of authors, in various countries, with regard to different target groups (Godwin and Carroll, 1986; Davies and Lea, 1995; Chien and Devaney, 2001; Eckel and Grossman, 2002; Ford and Kent, 2010; Rajna et al., 2011; Becchetti et al., 2011; Prabhakar, 2014; Agnew and Harrison, 2015). In general, this research has sought to identify how observable psychological factors shape people's financial literacy and behavior. Several 'attitude objects' have so far been identified, as shown in Table 1.

In the study of finances as an attitude object, 'financial attitude' has been a widely explored construct (Borden et al., 2008; Potrich, Vieira and Kirch, 2015; Garber and Koyama, 2016). Unfortunately, however, much of the extant attitudinal research appears to lack a sound theoretical foundation and unambiguous definition of attitude, and the term 'financial attitude' is often used to evoke different concepts (Word Bank, 2013). For instance, Garber and Koyama (2016) consider financial attitudes "as concerning how people feel (emotional), although they may include some aspects relating to knowledge (beliefs) and to behavior (predispositions)". On the other hand, according to Rajna et al., (2011) it is "the application of financial principles to create and maintain value through decision making and proper resource management". Differently again, Haque e Zulfiqar (2016) state that financial attitude "deals with ability to manage finances, interest of the individual in increasing financial knowledge, spending versus saving attitude and attitude toward taking risk while making an investment". As a consequence of this variety of definitions, the construct 'financial attitude' has also been operationalized and measured in different ways in different studies, making generalization difficult (Schrader and Lawless, 2004; Atkinson and Messy, 2012; Bongini et al., 2013; The Word Bank, 2013; Anz, 2015; Paluri and Mehra, 2016).

A crucial assumption, in the tradition of scientific literacy, is that it is improper to consider as perfect synonyms constructs such as (financial) "attitude", (financial) "aptitude" and "attitude toward" (finance); they are not interchangeable (Garder, 1975; Gauld and Hukins, 1980; Rao, 2010). Financial attitudes are thus not the same as financial aptitudes. Financial aptitude has so far received less attention from the academic community, with few exceptions.

\footnotetext{
${ }^{1}$ In this work, following the three-dimensional model of attitude by Di Martino and Zan (2010), attitude toward finance is characterised by three closely interrelated dimensions: view of finance, emotional disposition towards finance and perceived competence in finance. View of finance represents people's beliefs concerning the financial disciplines/practices/professions. Emotional disposition towards finance represents people's affective and emotional reactions of liking or disliking finance. Finally, perceived competence in finance indicates the self-beliefs that individuals hold regarding being able to succeed in the financial domain. Essentially, these three dimensions and their mutual combinations characterise an individual's relationship with finance and define his/her specific 'attitude profile' toward finance.
} 
Bongini et al (2013) are in fact the only researchers to have investigated the issue of university students' financial aptitude and provide evidence on the role of this non-observable trait in affecting financial literacy. They define financial aptitude as "one's particular inherent interest in financial matters", and attitude as "a way of looking at an issue or an object, a mental position or way of thinking about an issue". Their results confirm that financial aptitude is an interesting predictor of students' financial literacy. Furthermore, to the best of our knowledge, there are as yet no studies specifically exploring the 'attitude toward finance' construct. Attitude has so far been neglected as a variable in financial education studies, while it has longer history in other fields, such as science and mathematics education (Dutton and Stephens,1963; Ma and Kishor, 1997; Osborne, Simon and Collins 2003; Tahar et al., 2010).

Prior studies across different academic fields have identified several factors potentially related to the construct of attitude toward finance, including age, gender, personality, income and social origins. Ethnicity, educational background, experience/familiarity and peer behaviour are further factors influencing the construct(Osborne, 2003; Zamalia, 2009; Gifford and Sussman, 2012).Borrowing the definition used in other fields of study, specifically mathematics education, attitude towards finance can be expressed as the sum total of one's opinion, feelings and selfperception about financial issues (financial disciplines/practices/professions) (Di Martino and Zan, 2011).It is thus characterised by three closely interrelated dimensions: view of finance, emotional disposition towards finance and perceived competence in finance (Di Martino and Zan, 2010).

Some research has focused, at least briefly, on one single component of the construct, such as the view of finance of a given target group (Dobni and Racine, 2016; Driva, Lührmann and Winter, 2016), the emotional disposition toward finance of a particular segment of population (Burchell, 2002; Hanoch, 2002; Holden, 2010) or the financial selfconfidence of a specific target group (Danes and Haberman, 2007; Lapp, 2010; Arellano, 2014). Nevertheless, these analyses have been conducted independently, "in the same way as when measuring a physical object like a table one can decide whether to measure length, width or height" (Di Martino and Zan, 2015). No previous research has attempted to investigate all three of these variables on a single sample aimed at assessing the attitude to finance of a specific group of individuals or at drawing more general conclusions about the interrelation of these elements. The present study seeks to fill these gaps in the literature.

\section{Research method}

In order to identify women's perspectives on finance, we use a qualitative study based on focus group discussions. The aim is to ascertain women's perspectives on finance, highlighting their view of the financial world, the language they use and their feelings about finance as well as their perceived competence in this domain. Finance, viewed as a discipline of study, as a daily practice for financial well-being and as a possible career choice, can be positively or negatively evaluated. Focus groups are one of the most common methods of data collection in qualitative research. The technique is often used to explore themes that are not well-known in literature, as it can offer new insights and in-depth information regarding facts with which the researcher is not very familiar (Krueger, 1998; Morgan, 1988). Moreover, focus groups may make it possible to approach areas not otherwise easily accessible to quantitative methods. The topic of attitude toward finance does not in fact lend itself to observational techniques. Over the years, several attitude scales have been developed to measure attitude (Fennema and Sherman, 1976; Doepkenet al., 2003; Aiken, 1970; Moore and Sutman, 1970), but none refers specifically to the 'attitude toward finance' construct. For this study, we opted for focus groups as an appropriate data collection method in order to gather rich information, as women tend to be sensitive to question format and feel more comfortable with an open, free format than with multiple-choice questions (Wilkinson, 1999; Gallagher and De Lisi, 1994; Gipps and Murphy, 1994; Sternberg and Williams, 1995).Finally, note that this research method is used here for an exploratory stage of a larger research project in order to obtain preliminarily female responses on their relationship with finances, and thereby generate new hypotheses (Powell and Single, 1996).Focus group discussions were conducted between September 2016 and May 2018at the Department of Economics and Management at the University of Parmain Italy. They were managed by a team consisting of a moderator and an assistant moderator. The moderator facilitated the discussion and the assistant took notes and ran the tape recorder. Each session lasted approximately two hours. Participants from a range of age groups (19-65 years)and socioeconomic backgrounds were recruited through poster campaigns and social networks (Holbrook and Jackson, 1996). The advertisements provided information about the purpose of the study, interview duration, deadline for volunteering, selection criteria and incentive for participation. Of about 200 women contacted, 87 volunteers responded to the advertisement and participated in the interview. Their socio-demographic characteristics are shown in Table 2.A total of ten focus group discussions were conducted and each group ranged in size from five to eleven participants (Morgan, 1993). The majority of participants claimed to have never worked in the financial industry $(70.1 \%, 54$ respondents), while $29.9 \%$ said that they currently do so (23 respondents). 
Special attention was paid to composition of groups in order to cultivate a positive atmosphere during the discussions and promote a mutually respectful group dynamic (Morgan and Krueger, 1993; Kitzinger, 1994; Grønkjæret al. 2011; Morgan, 2013). All participants felt comfortable with each other during sessions, and were able to share their views, including conflicting opinions, without inhibitions. During the meeting, the moderator used a prepared script to welcome participants, remind them of the purpose of the group and provide some guidelines. In order to elicit and collect the desired information from the participants, a semi-structured interview guide was used(Buttner,2001). This pre-determined list of open-ended questions was largely inspired by Di Martino and Zan's (2010) theoretical framework and was appropriately adapted for this context. Detailed discussions included exploring participants' view of finance, their emotional disposition toward finance, and their perceived competence in the financial field. The protocol consisted of three parts (Table 3 ).

The moderator used a funnel approach, moving from broader topics to more specific questions during each session. In order to better stimulate discussion around the research problem, practical projective techniques including metaphor techniques, analogies and word and imagery associations were used to access respondents 'core beliefs and reveal their underlying emotions about the target domain. With the respondents' permission, all focus group discussions were tape-recorded. Transcript-based analysis, the most rigorous and time-intensive mode was used to analyse data. In order to identify the interpretative codes, the template method(King, 1998), combing theory-driven and data-driven approaches was used, and to examine the textual content, T-Lab 9.1, a content analysis software package, was used. Results are presented and discussed in Section 4. Finally, to better investigate the potential relationships between the qualitative variables, the different constitutional dimensions of the attitude and the socio-demographic data of the respondents, the main association indexes were also calculated. The results of the parametric conducted tests are reported in Section 5.

\section{Main results}

To begin the discussion sessions, focus groups participants were asked to talk about their personal view of the financial sector as a whole. The moderator showed them a range of pictures (see Appendix 1) and asked the respondents to select the image that best represented their personal view of the financial word, and provide a description. This started discussion on the subject. The 'House of Cards' image was the most frequent choice (Figure 1).Discussions showed that the underlying perception was that the financial system is a very fragile world, where if one bank fails, they all fail. A non-negligible proportion of the respondents believe that the entire financial system is a keg of dynamite ready to explode, as during the recent financial crisis. The picture 'Calculation' also scored highly. Interestingly, a key issue to emerge was that finance is considered to be a maths-intensive subject; respondents associated finance closely with concepts such as mathematics, volatility, statistics, and graphs. Another image frequently selected was entitled 'Learning, commitment, and employment'. In this case, respondents placed particular emphasis on the intrinsic difficulty of financial disciplines. Often, finance was labelled as a complex subject, unapproachable for non-experts because ofits technical and unfamiliar language. During discussions, several respondents also described how finance required a particular kind of intelligence, especially given its quantitative nature.

Secondly, respondents were asked to compare a bank to an animal. This elicited common patterns as well as various original and unusual responses. In general, many young women were inclined to associate banks with felines such as leopards, tigers, and lions. These animals inspire feelings of awe, fear, and dread, and this association implies that financial services are essentially viewed as an unsafe and intimidating environment. Older women often found an association with hyenas, condors, rattlesnakes, or foxes, confirming that financial services suffer from an image problem and tarnished reputation amongst this group. A few respondents took a more benevolent or neutral view of the financial sector, and suggested metaphorical connections between financial institutions and social insects, such as ants and bees, to highlight the essential social role of the financial sector in society.

Thirdly, the moderator asked participants to cite the most important traits required of successful leaders in financial services (see Figure 2). Overall, they were seen as 'dominant', 'ambitious', 'charismatic 'and 'career-oriented'. As further key traits, the participants also mentioned astuteness, rashness, competitive spirit, technical competence, and mastery of numerical skills. Regardless of age, the women expressed similar perceptions these characteristics, differing only in the degree to which qualities were emphasized. In general, several of these leadership traits were stereotypically associated with masculinity. Doubts about the compatibility between a male-dominated profession such as finance and banking and important parts of female identity were also raised by a number of women. Mostly older women emphasised that the financial profession requires characteristics and hard skills (rationality, expediency, numeracy) which are not consistent with their feminine self-image. 
Some interviewees also cited the psychological and financial costs of a career in finance, most notably in terms of sacrifice in personal life, including not meeting cultural expectations or becoming more androgynous in the attempt to adapt to the dominant male culture.

Participants then were asked to associate finance with a gender in order to gather further opinions on gender beliefs about finance. Not surprisingly, a large majority of women associated finance with 'male', while the gender neutral option was the second most frequent answer. The portrayal of the sector by Hollywood and mass media, the cultural norms, and the absence of female financial role models were identified as the main factors in the prevailing stereotypical image of the finance industry as a male-dominated environment. Conversely, respondents who opted for a gender neutral association stated that nowadays it is not unusual for a woman to select a finance-intensive major or a career in finance and succeed. Finally, only a minority of respondents associated finance with female, but although the option was selected sporadically, some of the respondents put forward interesting, unusual ideas. For example, in one group, one woman who opted for the finance-female association made this unexpected comment:

"Market fluctuations remind me of feminine instability: they are similar to a woman's hormonal ups and downs!'Respondents were then asked to explain how they feel about finances in order to assess their emotional response to financial issues. Overall, many respondents reported slightly more negative feelings than positive; not surprisingly, these unfavourable feelings were detrimental to their interest and engagement with financial content. Anxiety, concern, confusion, boredom and inadequacy in their finances were ubiquitous across focus-group participants, regardless of age, and many women confessed that they felt insecure, anxious, and detached when dealing with financial issues. Dissatisfaction with the way financial companies serve them and annoyance were other reactions found repeatedly. Additionally, many older participants felt overwhelmed, unable to seek professional advice and unable to develop financial skills at an advanced age. Younger women (aged 19-35) reported more ambivalent feelings toward financial issues. In this age band, excitement and curiosity towards financial matters, perceived as complex and not well-known, and for this reason, intriguing, sometimes coexisted with worry, confusion and boredom.

Conversely, less than a third of the respondents stated that they had neutral or positive feelings towards finance. Especially women who held a finance degree and/or were making a career in the field of finance were slightly more likely to feel happy, at ease and even excited when dealing with financial issues and tasks. Finally, when respondents were asked to express the degree of perceived self-efficacy and confidence to learn finance and perform financial tasks, another mixed picture emerged (Figure3). Women who had an educational or professional background in finance, business, economics or management showed higher levels of self-concept (belief on their own financial capabilities) and self-efficacy (belief in their own ability to solve specific financial tasks). They also reported spending time dealing with financial issues and finding this fun and interesting. The rest of respondents however reported low confidence in their financial skills, and that they delegate a spouse or partner, if there is one, or a financial advisor to manage the financial aspects of their life.

\section{Discussion}

One of the purposes of this exploratory focus group study was to generate hypotheses for future research and to examine whether and how a number of personal variables, including age, educational and/or professional path, influence attitude toward finance among women. The aim was to ascertain whether such variables can predict whether an individual is likely to have a strongly favourable attitude, or hold an aversion, toward finance. We therefore developed a set of testable hypotheses on the theme which subsequent quantitative research should be able to confirm. This qualitative study is inductive and exploratory, and the hypotheses outlined below were not formulated at the outset of the investigation, but only tentatively proposed during the iterative process of data collection and interpretation. They were non-directional in their predictions as well as general. They were as follows:

H1: Age predicts attitude toward finance

$\mathrm{H} 2$ : Area of origin predicts attitude toward finance

H3: Marital Status predicts attitude toward finance

H4: Education predicts attitude toward finance

H5: Educational path in finance predicts attitude toward finance

H6: Work History predicts attitude toward finance

$\mathrm{H7}$ : Career path in finance predicts attitude toward finance 
A chi square analysis ${ }^{2}$ was conducted to test whether there was any significant association between attitude toward finance and the above variables (age, area of origin, marital status, professional and educational path, professional and educational path in finance). The results are presented in the following tables (Tables 4, 5 and 6).If the P-value is less than 0.10 , the nominal level for statistical significance, we conclude that there is evidence of a statistically significant difference in the attitude toward finance between the two groups. However, this non-parametric test (Chi-squared test) is simply a hypothesis test. It merely indicates whether a difference is likely, given the null hypothesis of no difference. No information is given about the likely size of the difference, and so whilst we can conclude that there is a significant difference between the two groups with regard to attitude toward finance, no conclusions about the possible size of the difference can be drawn. Given this premise, the results show a clear relationship between attitude toward finance, in all its components, and an educational or professional path in finance. In particular, Table 4 presents the association measures between attitude toward finance and the socio-demographic variables which describe respondents. Results show clearly a statistically significant relationship between the attitude to finance variable and the two variables indicating an education or professional path in the field of finance. In both cases, the values close to zero taken by $\square 2$ tests confirm a link between variables.

Respondents' attitude toward finance thus appears to be influenced by their education and/or their career path, and whether these have been financial in nature. There is also a relationship, although weaker (statistical significance 10\%) with the variable "area of origin". Finally, there seems to be no relationship between attitude toward finance and other variables, including age.

Only Hypotheses 2, 5 and 7 are supported. Hypotheses 1, 3, 4 and 6 are not supported, and no significant relationship was found between these variables and attitude toward finance in the sample. In other words, no evidence was found that age, marital status, and education or work experience influence a woman's attitude toward finance. In order to deepen the analysis, the associations between the various components of attitude toward finance and the sociodemographic variables listed above were then calculated to find out whether the relationship between the variables changes.

The results in Table 5 confirm the relationship already noted and show that there is no dimension of attitude toward finance for which the relationship appears different. The relationship between attitude to finance and education / professional path in finance is valid for all components of attitudes toward finance and has the same statistical significance. In other words, an education or professional path in finance seems to be able to influence all the components of a woman's attitude towards finance (view of finance, emotional disposition toward finance, and perceived competence in finance).Only the variable "Area of origin" differs in this. For this variable, there is a relationship only with the second dimension of attitude, i.e. "emotional disposition toward finance". Being born in a particular area seems to have an impact on an individual's emotional disposition towards finance. Again, relations with other variables (including age) remain statistically not significant. Finally, association measures (see Table 6) were used to investigate the first component of ATF, view of finance, subdivided into sub-components. The results show that the relationships highlighted above do not change: the "image", "animal" and "trait" sub-variables are linked to both variables "educational path in finance" and "professional path in finance" with statistical significance at 1\%. For the "gender" variable, the relationship has lower statistical significance at5\%. The variables "animal" and "trait" are also linked to the area of origin.

\section{Conclusions}

Today, the requirement for financial skills pervades society, and financial knowledge is an essential tool for individuals and households. The relative financial ignorance of women has become a global concern over the years. The conviction prompting this study is that financial literacy is not only a cognitive challenge, but also an affective one (Atkinson et al., 2006; Johnson and Staten, 2010; Bongini et al., 2013, OECD, 2013a; Arellano et al., 2015; OECD,2015). There has been a sizeable amount of research on financial literacy, but limited attention has been given to 'attitude toward finance'. To our knowledge there has been very little research focussing on the three dimensions of attitude toward finance (beliefs about finance, affect towards finance and perceived competence in the field) in a single model, and little is known on the topic. The starting point of our investigation is the notion that collectively women may have a negative attitude toward finance, which may constitute a barrier to their acquisition of financial knowledge. If this were shown to be the case, a novel explanation for gender gaps in financial knowledge could be explored.

\footnotetext{
${ }^{2}$ Using the group as the unit of analysis is the most common method of data analysis. Simple statistical frequencies are most effective in depicting the more important characteristics of the problem being investigated. More complex statistical analyses are not feasible because of the limited, and primarily qualitative, nature of the data. Given that the number of focus groups was sufficiently large, the chi-squared test of significance can be applied. 
In this preliminary study, a focus group method is used to bridge this gap in knowledge in the literature and explore female attitude toward finance. The study investigates how women in the sample perceive and feel "finance", and ascertains whether and to what extent attitude varies on the basis of age and their educational/professional background. As a preliminary investigation, this research offers a brief 'snapshot' of these issues. Our findings in fact suggest that in the population studied, there is a complex combination of factors which shape women's attitudes towards finance. External factors may include family financial history, parental attitudes to finance, the media's portrayal of the financial sector, attitudes of peers and friends towards finance. It is likely however that internal variables, such as gender, age, personality traits, cultural background, professional and educational path, values and motives, also play an important role. In sum, we find no difference in attitude to finance in the sample on the basis of age, while there are differences on the basis of respondents' educational and/or professional background. It can be hypothesized that this finding reflects the significant roleof the degree of familiarity with the attitude object as an important predictor of attitude. In fact, more frequent and direct experience with finance appears to contribute to developing a favourable attitude, strengthening in particular the affective component.

This study has several limitations. First, by their nature, the findings of a focus group research are not representative of the general population and are subject to restrictions on their generalizability. Selection bias is a second methodological concern. A third weakness is the choice of an exclusively female sample; the study could have benefited from including men in the sample for purposes of comparison. A differentiated gender composition would clearly have been essential to highlight differing perspectives, and could have revealed whether gender isa significant factor influencing the construct.

Researcher bias, one of major concerns in qualitative research overall, is another possible limitation, in that the unstructured and qualitative nature of the focus-group data makes summary analysis and interpretation of findings a subjective process. The final limitation of this exploratory studyhas to do with the fact thatattitudes to finance is not studied in relation to financial knowledge.

Nevertheless, as qualitative research, this study offers innovative contributions and suggestions which would probably not have been uncovered by a quantitative survey and which are useful for the somewhat under-researched debate on attitude toward finance. The innovation of including different variables in a single model to assess attitudes toward finance is important, as previously previous financial literacy studies examined them only separately. The study thus differs from existing ones in the field in terms of both theoretical perspective and methodological approach. Finally, this is a preliminary study and only an initial attempt to explore the construct of attitude toward finance and some of the factors which may influence it. The suggestions and hypotheses emerging from this paper require testing and validation through more quantitative analysis. Quantitative research in fact is clearly required to explore the effects of factors such as age, gender, and other socio-demographic variables, on individuals' attitude toward finance. Future research would also be useful to investigate whether a negative attitude to finance can be a barrier to the acquisition of financial knowledge, and vice versa. Exploring this assumption is an interesting avenue for further study. As a practical implication, monitoring of attitude toward finance and attitude change techniques should become key elements in financial education schemes. To conclude, new and stimulating research are available which would further allow us to continue our inquiries in the field and there are a great many possible future advantages in pursuing these lines of research.

\section{Table and Figures}

Table 1 -Brief Summary of papers identified for systematic review (Attitudes in the financial field)

\begin{tabular}{|c|l|}
\hline 'Entity' evaluated & \multicolumn{1}{c|}{ Papers } \\
\hline Money attitudes & $\begin{array}{l}\text { Roberts and Jones, 2001; Norvilitis et al., 2006; Falahati, 2011; Rinaldi and Todesco, } \\
2012\end{array}$ \\
\hline $\begin{array}{c}\text { Attitudes toward financial } \\
\text { management }\end{array}$ & Godwin and Carroll, 1986; Rajna et al. 2011 \\
\hline Financial market attitudes & Ford and Kent, 2010 \\
\hline Investment attitudes & Becchetti et al., 2011 \\
\hline Attitudes toward debt & Davies and Lea, 1995; Agnew and Harrison, 2015 \\
\hline
\end{tabular}


Risk attitudes

Attitudes toward credit and finances

Financial attitudes

Financial aptitudes

Attitude toward finance

Source: Own elaboration.
Schubert et al., 1999; Croson and Gneezy, 2009; Eckel and Grossman, 2002

Chien and Devaney, 2001; Norvilitis and Mendes-Da-Silva, 2013

Rajna et al. 2011; Garber and Koyama, 2016; Haque and Zulfiqar, 2016

Bongini et al., 2013

To date, no study has investigated this construct

Table 2 - Characteristics of the respondents

\begin{tabular}{|l|ll|}
\hline & Frequency & Percentage (\%) \\
\hline 1. Age & $\mathbf{8 7}$ & $\mathbf{1 0 0}$ \\
a) 19 to 35 & 39 & 44.8 \\
c) 36 and over & 48 & 55.2 \\
\hline 2. Area of origin & $\mathbf{8 7}$ & $\mathbf{1 0 0}$ \\
a) NorthernItaly & 42 & 48.3 \\
b) Central Italy & 18 & 20.7 \\
c) Southern Italy & 22 & 25.3 \\
d) Foreignborn & 5 & 5.7 \\
\hline 3. Educational Attainment & $\mathbf{8 7}$ & $\mathbf{1 0 0}$ \\
a) high schoolcertificate & 50 & 57.5 \\
b) first cycleuniversitydegree & 31 & 35.6 \\
c) secondcycleuniversitydegree, doctorate or similar & 6 & 6.9 \\
\hline 4. Education in finance & $\mathbf{8 7}$ & $\mathbf{1 0 0}$ \\
a) yes & 28 & 32.2 \\
b) no & 59 & 67.8 \\
\hline 5.EmploymentHistory & $\mathbf{8 7}$ & $\mathbf{1 0 0}$ \\
a) no experienceof work & 32 & 36.8 \\
b) employee & 36 & 41.4 \\
c) self-employed & 19 & 21.8 \\
\hline 6. Career in finance & $\mathbf{8 7}$ & $\mathbf{1 0 0}$ \\
a) yes & 23 & 26.4 \\
b) no & 54 & 62.1 \\
\hline 7. Marital Status & $\mathbf{8 7}$ & $\mathbf{1 0 0}$ \\
a) single & 42 & 48.3 \\
b) cohabitant & 15 & 17.2 \\
c) married & 23 & 26.4 \\
d) divorced & 7 & 8.0 \\
\hline Source Own elabortion & &
\end{tabular}

Source: Own elaboration.

Table 3 - Selected questions from the Guide for focus group discussions

\begin{tabular}{|ll|}
\hline & I VIEW OF FINANCE \\
& Which pictures best describe your personal view of the financial world? \\
& If a bank were an animal, what would it be? \\
\hline & Which words best describe the most important trait required for a successful leader in financial services? \\
Do you perceive finance as a male, female, or gender-neutral subject? \\
emotional responses to financial issues do you have (i.e., feelings of hopelessness, inadequacy, stress, boredom, \\
confusion, or interest, enthusiasm, enjoyment, sense of mastery)?
\end{tabular}

${ }^{3}$ Average age $=35.3 ;$ Min age $=19 ;$ Max age $=65$. 


\section{PERCEIVED COMPETENCE IN FINANCE}

. On a scale from 1 to 7 , how confident are you in your understanding of financial topics/in your ability to succeed in financial activities? ( 1 - not confident at all... 7 - completely confident)

Figure 1: Most frequent responses to the question "Which pictures best describe your personal view of the financial world?"

\begin{tabular}{|l|l|}
\hline \multicolumn{2}{|c|}{ Top Ranked Picture } \\
\hline $\mathbf{1}^{\circ}$ & House of cards \\
\hline $\mathbf{2}^{\circ}$ & Calculation \\
\hline $\mathbf{3}^{\circ}$ & Learning, commitment, employment \\
\hline
\end{tabular}

Source: Own elaboration.

Figure 2: The key traits of successful leaders in financial services

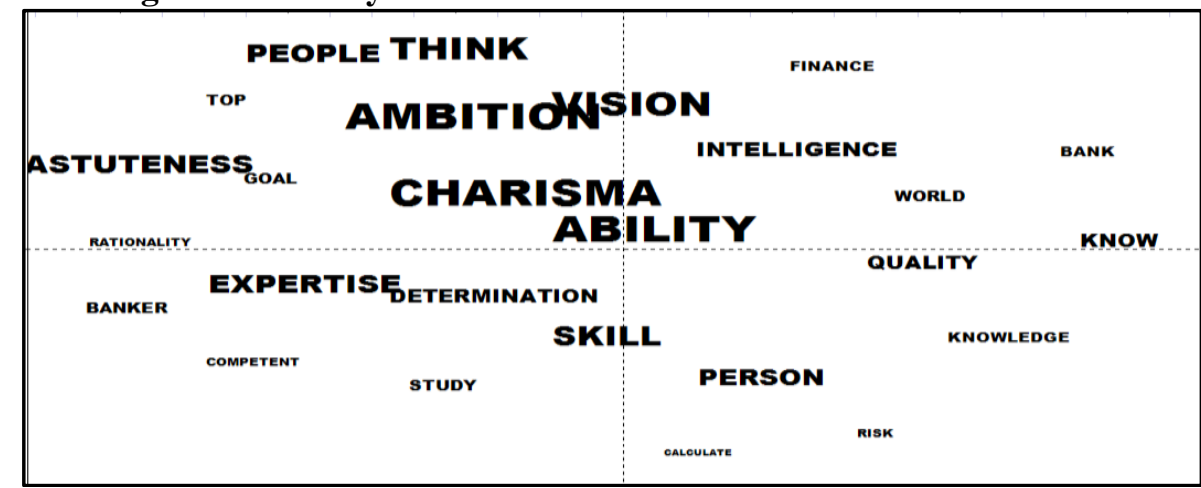

Source: Produced by T-Lab Software.

Note: Figure 2 is a visual map developed by T-Lab software giving an overview of the most frequent keywords appearing in responses. The minimum frequency threshold is set to 4 to guarantee the reliability of the statistical procedures. The dimension of a word in the map shows the weight of the term within the discourse. The map shows thatsuccessful leaders in financial services were commonly seen as ambitious, charismatic, astute, determined and skilful.

Figure3: Perceived competence in Finance on a scale from 1 to 7

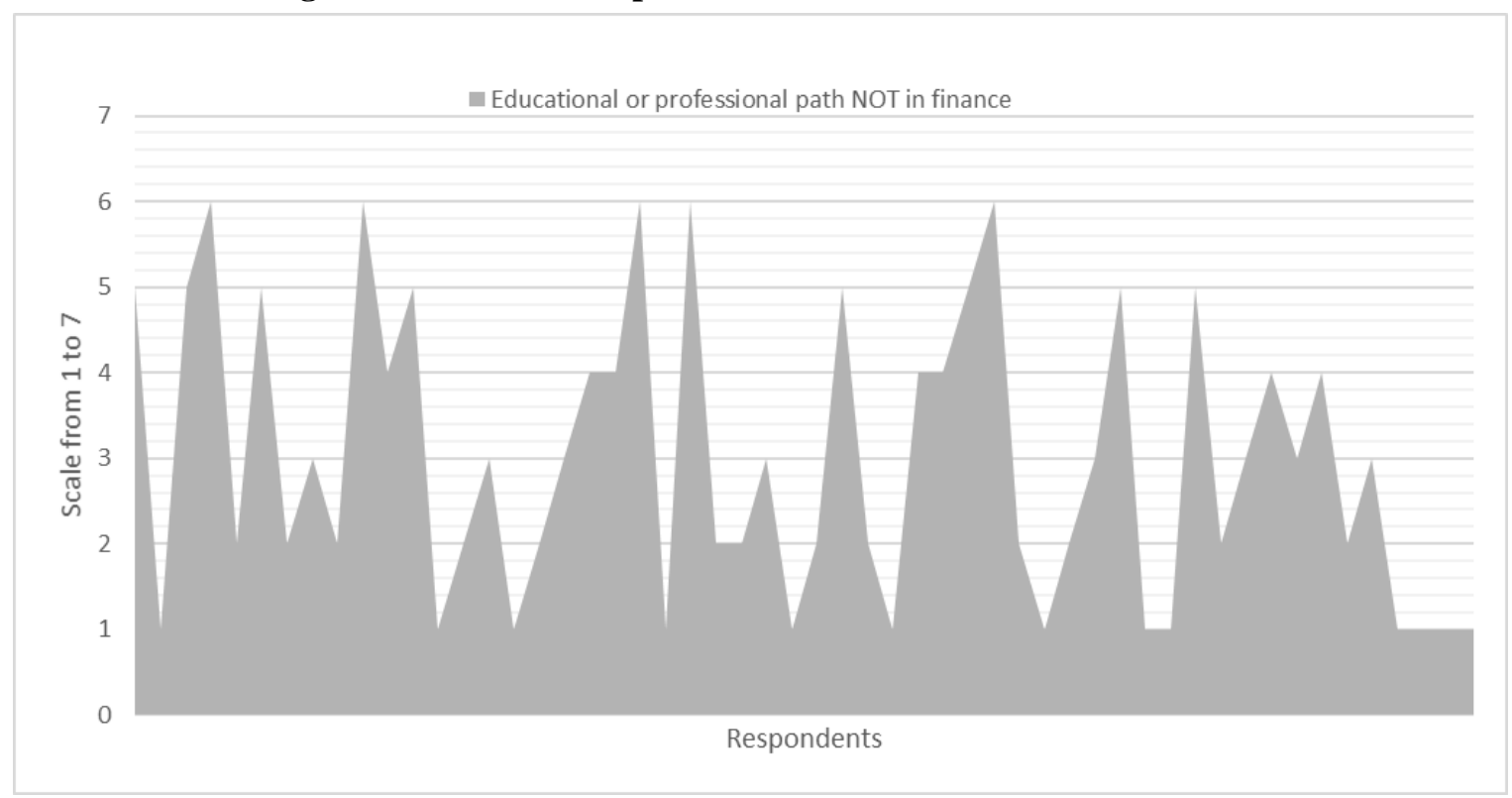




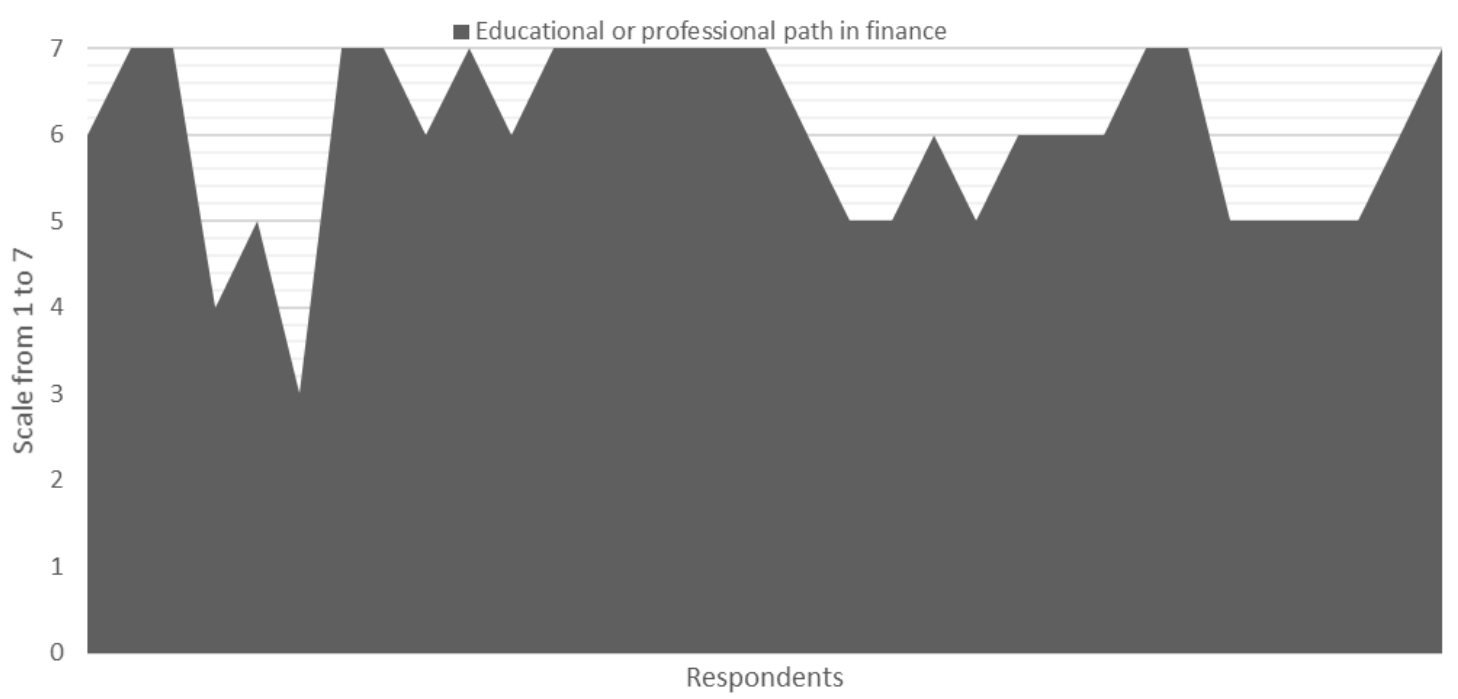

Source: Own elaboration.

Note: The two graphs show responses to the question "On a scale from 1 to 7 , how confident are you in your understanding of financial topics/in your ability to succeed in financial activities?(1 - not confident at all ... 7 - completely confident)". Here, respondents are divided into two groups according to their education or professional area as a proxy of their degree of familiarity with the field. The first group are women who do not have an educational / professional path in finance. For these women, the perception of their own financial skills is limited. The second groupis made up of women who had education or professional employment in the field of finance. Here, levels of perception and self-confidence are clearly higher.

Table 4 - Measures of association between "Attitude to Finance" (ATF) and socio-demographic variables

\begin{tabular}{|c|c|c|c|c|c|c|c|}
\hline & Age & $\begin{array}{l}\text { Area of } \\
\text { origin }\end{array}$ & $\begin{array}{l}\text { Marital } \\
\text { status }\end{array}$ & $\begin{array}{l}\text { Educational } \\
\text { attainment }\end{array}$ & $\begin{array}{l}\text { Educational } \\
\text { path in } \\
\text { finance }\end{array}$ & $\begin{array}{l}\text { Work } \\
\text { experience }\end{array}$ & $\begin{array}{l}\text { Career path in } \\
\text { finance }\end{array}$ \\
\hline \multicolumn{8}{|l|}{ ATF } \\
\hline PhiCoefficient & 0,002 & $0,329 *$ & 0,028 & 0,183 & $0,557 * * *$ & 0,139 & $0,552 * * *$ \\
\hline Cramer's V & 0,002 & $0,329 *$ & 0,028 & 0,183 & $0,557 * * *$ & 0,139 & $0,552 * * *$ \\
\hline \multicolumn{8}{|c|}{$\begin{array}{l}\text { The probabilitieswerecalculatedbased on the Pearson } \square 2 \text { test and the Likelihood Ratio test (or G method). } \\
\text { The statisticalsignificanceisindicated by means of asterisks: } \\
* * * \text { - statisticalsignificanceat } 1 \% \\
\text { ** - statisticalsignificanceat } 5 \% \\
* \text { - statisticalsignificanceat } 10 \%\end{array}$} \\
\hline
\end{tabular}

Source: Own elaboration.

Table 5 - Measures of association between "Attitude toward Finance" components - (1) view of finance, (2) emotional disposition toward finance, (3) perceived competence in finance - and socio-demographic characteristics of the respondents

\begin{tabular}{|c|c|c|c|c|c|c|c|}
\hline & Age & $\begin{array}{l}\text { Area } \\
\text { of } \\
\text { origin }\end{array}$ & $\begin{array}{l}\text { Marital } \\
\text { status }\end{array}$ & $\begin{array}{l}\text { Educational } \\
\text { attainment }\end{array}$ & \begin{tabular}{|l|} 
Educational \\
path in \\
finance
\end{tabular} & $\begin{array}{l}\text { Work } \\
\text { experience }\end{array}$ & $\begin{array}{l}\text { Career } \\
\text { path in } \\
\text { finance }\end{array}$ \\
\hline \multicolumn{8}{|c|}{ 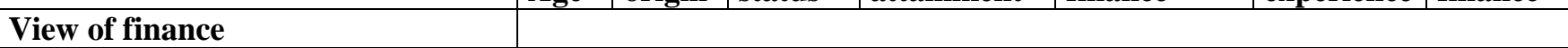 } \\
\hline PhiCoefficient & 0,096 & 0,281 & 0,145 & 0,195 & $0,500 * * *$ & 0,156 & $0,479 * * *$ \\
\hline Cramer's V & 0,096 & 0,281 & 0,145 & 0,195 & $0,500 * * *$ & 0,156 & $0,479 * * *$ \\
\hline \multicolumn{8}{|c|}{\begin{tabular}{|l|l|l|} 
Emotionaldispositiontowardfinance & & \\
\end{tabular}} \\
\hline PhiCoefficient & 0,059 & $0,345^{*}$ & 0,083 & 0,149 & $0,501 * * *$ & 0,074 & $0,528 * * *$ \\
\hline Cramer's $V$ & 0,059 & $0,345^{*}$ & 0,083 & 0,149 & $0,501 * * *$ & 0,074 & $0,528 * * *$ \\
\hline Perceivedcompetence in finance & & & & & & & \\
\hline
\end{tabular}




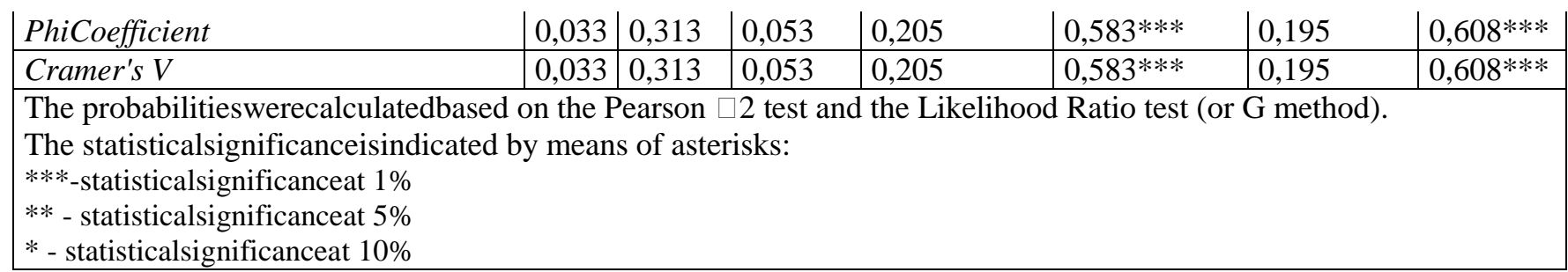

Source: Own elaboration.

Table 6 - Measures of association between components of "Vision of Finance" and socio-demographic characteristics of the respondents

\begin{tabular}{|c|c|c|c|c|c|c|c|}
\hline & Age & $\begin{array}{l}\text { Area of } \\
\text { origin }\end{array}$ & $\begin{array}{l}\text { Marital } \\
\text { status }\end{array}$ & $\begin{array}{l}\text { Educational } \\
\text { path }\end{array}$ & $\begin{array}{l}\text { Educational } \\
\text { path in } \\
\text { finance }\end{array}$ & $\begin{array}{l}\text { Professional } \\
\text { path }\end{array}$ & \begin{tabular}{|l|} 
Professional \\
path in \\
finance
\end{tabular} \\
\hline \multicolumn{8}{|l|}{ Image } \\
\hline PhiCoefficient & 0,172 & 0,191 & 0,209 & 0,138 & $0,402 * * *$ & 0,162 & 0,480 *** \\
\hline Cramer's V & 0,172 & 0,191 & 0,209 & 0,138 & $0,402 * * *$ & 0,162 & $0,480 * * *$ \\
\hline \multicolumn{8}{|l|}{ Animal } \\
\hline PhiCoefficient & 0,071 & $0,339^{*}$ & 0,103 & 0,113 & $0,467 * * *$ & 0,175 & 0,386 ** \\
\hline Cramer's V & 0,071 & $0,339 *$ & 0,103 & 0,113 & $0,467 * * *$ & 0,175 & $0,386 * *$ \\
\hline \multicolumn{8}{|l|}{ Trait } \\
\hline PhiCoefficient & 0,074 & $0,341 *$ & 0,090 & 0,176 & $0,344 * * *$ & 0,171 & $0,507 * * *$ \\
\hline Cramer's V & 0,074 & $0,341^{*}$ & 0,090 & 0,176 & $0,344 * * *$ & 0,171 & $0,507 * * *$ \\
\hline \multicolumn{8}{|l|}{ Gender } \\
\hline PhiCoefficient & 0,011 & 0,235 & 0,090 & 0,199 & $0,255^{* *}$ & 0,111 & $0,273 * *$ \\
\hline Cramer's V & 0,011 & 0,235 & 0,090 & 0,199 & $0,255^{* * *}$ & 0,111 & $0,273 * *$ \\
\hline \multicolumn{8}{|c|}{$\begin{array}{l}\text { The probabilitieswerecalculatedbased on the Pearson } \square 2 \text { test and the Likelihood Ratio test (or G method). } \\
\text { The statisticalsignificanceisindicated by means of asterisks: } \\
* * * \text {-statisticalsignificanceat } 1 \% \\
* * \text { - statisticalsignificanceat } 5 \% \\
* \text { - statisticalsignificanceat } 10 \%\end{array}$} \\
\hline
\end{tabular}

\section{Source: Own elaboration.}

Note: (1 - Image)Which pictures best describe your personal view of the financial world? ( 2 - Animal)If a bank were an animal, what would it be? (3 - Trait) Which words best describe the most important trait required for a successful leader in financial services? (4 Gender) Do you perceive finance as a male, female, or gender-neutral subject?

\section{References}

AA.VV. (byPattiChiari) (2014), Le Competenze economico-finanziarie degli Italiani, Roma, Bancaria editrice.

S. Agnew - N. Harrison (2015), "Financial literacy and student attitudes to debt: A cross national study examining the influence of gender on personal finance concepts", Journal of Retailing and Consumer Services, Vol. 25, pp. 122-129".

ANZ (2015), Anz Survey of Adult. Financial Literacy in Australia, May.

A. Arellano - N. Cámara - D. Tuesta (2014), "The effect of self-confidence on financial literacy", BBVA Research, 14/28Working Paper, October.

A. Arellano - N. Cámara - D. Tuesta (2015), "Explaining the Gender Gap in Financial Literacy: the Role of NonCognitive Skills", BBVA Research 15/32 Working Paper, December.

Assogestioni - Accademia delle Belle Arti di Brera (2011), "Le metafore del risparmio", Il Salone del Risparmio, Milano,Nomos Edizioni.

A. Atkinson - S. McKay - E. Kempson - S. Collard (2006), "Levels of Financial Capability in the UK: Results of a baseline survey", Financial Services Authority.

L. Becchetti- S. Caiazza- D. Coviello (2011), "Financial education and investment attitudes in high schools: evidence from a randomized experiment”, Research Paper Series, 9 (10). 
P. Bongini - P. Trivellato P. - M. Zenga (2013), "Financial Literacy and Undergraduates: A Question of Aptitude?", September. Available at SSRN: http://ssrn.com/abstract=2325316.

Y. W. Chien - S. A. Devaney (2001), "The Effects of Credit Attitude and Socioeconomic Factors on Credit Card and Installment Debt", Journal of Consumer Affairs, 35, pp. 162-179.

S. Danes - H. Haberman (2007), "Teen Financial Knowledge, Self-Efficacy, and Behavior: A Gendered View", Financial Counseling and Planning, 18, 2, pp. 48-60.

S. Del Prete- M.L. Stefani (2013), "Women on Italian bank boards: are they 'gold dust'?", Banca d'Italia, Occasional Papers, n. 175.

E. Davies - S.E.G. Lea (1995), "Student attitudes to student debt”, Journal of Economic Psychology, 16 (4), pp. 663679.

P. Di Martino - R. Zan (2010), 'Me and maths': Towards a definition of attitude grounded on students' narratives”, Journal of Mathematics Teacher Education, 13, 1, pp. 27-48.

P. Di Martino - R. Zan (2011), "Attitude towards mathematics: a bridge between beliefs and emotions", ZDM: The International Journal on Mathematics Education, 43, pp. 471-482.

P. Di Martino - R.Zan (2015), The Construct of Attitude in Mathematics Education. In B. Pepin \& B. Roesken-Winter (Eds.), From beliefs to dynamic affect systems in mathematics education (pp. 51-72). Switzerland: Springer International Publishing.

W.Dutton - L. Stephens (1963), Measuring attitudes toward science. School Science and Mathematics, 1963, 63, 4349.

C. C. Eckel- P. J. Grossman (2002), "Sex differences and statistical stereotyping in attitudes toward financial risk",Evolution and Human Behavior 23 (4), pp. 281-295.

S. Galeazzi (2012), "Genere e scelte formative: le minoranze di genere", Almalaurea workingpapers, 53.

A.M. Gallagher - R. De Lisi (1994), "Gender differences in scholastic aptitude test mathematics problem solving among high ability students", Journal of Educational Pshycology, 86(2)

G. Garber - S. M. Koyama (2016), "Policy-effective Financial Knowledge and Attitude Factors", Working Papers Series 430, Central Bank of Brazil, Research Department.

P. L. Gardner (1975), "Attitudes to Science: A Review”, Studies in Science Education 2.

C. F. Gauld - A. A. Hukins (1980), "Scientific attitudes: a review", Studies in Science Education, 7, pp. 129-161.

C. Gipps - P. Murphy (1994), A fair test: Assessment, achievement and equity, Buckingham, Open University Press.

B. Glaser - A. Strauss (1967), The discovery of grounded theory: Strategies for qualitative research, New York: Aldine Publishing Company.

D. D. Godwin- D. D. Carroll (1986), "Financial management attitudes and behaviour of husbands and wives", Journal of Consumer Studies and Home Economics, 10, pp. 77-96.

Y. Hanoch (2002), "Neither an angel nor an ant: Emotion as an aid to bounded rationality", Journal of Economic Psychology, 23, pp. 1-25.

A. Haque- M. Zulfiqar (2016), "Women's Economic Empowerment through Financial Literacy, Financial Attitude and Financial Wellbeing", International Journal of Business and Social Science, Vol. 7, No. 3; March.

N. Harrison - S. Agnew, J. Serido (2015), "Attitudes to debt among indebted undergraduates: A cross-national exploratory factor analysis", Journal of Economic Psychology / Elsevier, 46, pp. 62-73.

B. Holbrook - P. Jackson (1996), "Shopping around: focus group research in North London", Area 28 (2), pp. 136-42.

M.J. Hoppe - E.A. Wells - D.M. Morrison- M.R. Gilmore - A. Wilsdon (1995), "Using focus groups to discuss sensitive topics with children", Evaluation Review 19 (1), pp. 102-14.

C. Johnson - M. Staten (2010), "Do inter-temporal preferences trump financial education courses in driving borrowing and payment behavior?", Article presented at the 1st Annual Boulder Conference on Consumer Financial Decision Making, June.

J. Kitzinger (1995), "Introducing focus groups", British Medical Journal, 311, pp. 299-302.

L. Klapper - A. Lusardi - P. van Oudheusden (2015), Financial Literacy Around the World: Insights from the Standard and Poor's Ratings Services Global Financial Literacy Survey, McGraw Hill Financial.

R. A. Krueger (1994), Focus groups: A practical guide for applied research (2nd ed.), Thousand Oaks, CA Sage.

A.J. Lankshear (1993), "The use of focus groups in a study of attitudes to student nurse assessment", Journal of Advanced Nursing, 18, pp.1986-1989.

W. M. Lapp (2010), "Behavior models for prosperity: A statistical assessment of savings and behavioral change", EARN Research Brief, San Francisco, Earned Assets Resource Network.

A. Lusardi - O. S. Mitchell (2008), "Planning and Financial Literacy: How Do Women Fare?", American Economic Review, 98(2), pp. 413-417. 
X.Ma -N.Kishor (1997), Assessing the relationship between attitude toward mathematics and achievement in mathematics: A meta-analysis. Journal for Research in Mathematics Education, 28(1), 27-47.

D.L. Morgan (1988), Focus groups as qualitative research, London: Sage.

D.L. Morgan (1993), Successful focus groups: Advancing the state of the Art, Newbury Park: SAGE Focus Edition.

C. Noè (2012), "Genere e scelte formative", AlmaLaureaWorkingPapers, n.54.

J. M.Norvilitis-W.Mendes-Da-Silva (2013), "Attitudes toward credit and finances among college students in Brazil and the United States", Journal of Business Theory and Practice, 1 (1), pp. 132-151.

OECD (2011), Report on the Gender Initiative: Gender Equality in Education, Employment and Entrepreneurship, Meeting of the OECD Council at Ministerial Level Paris, 25-26 May.

OECD (2013a), PISA 2012 Assessment and Analytical Framework. Mathematics, Reading, Science, Problem Solving and Financial Literacy, Paris, OECD Publishing.

OECD (2013b), Women and Financial Education: Evidence, Policy Responses and Guidance, Paris, OECD Publishing.

OECD (2014), PISA 2012 Results: Students and Money: Financial Literacy Skills for the 21st Century, (Volume VI), PISA, OECD Publishing.

OECD (2015), PISA The ABC of Gender Equality in Education: Aptitude, Behaviour, Confidence, PISA, OECD Publishing.

J. F.Osborne - S. Simon - S. Collins (2003), Attitudes towards Science: A review of the literature and its implications. International Journal of Science Education, 25, 1049-1079.

R. A. Paluri - S. Mehra (2016), "Financial attitude based segmentation of women in India: an exploratory study", International Journal of Bank Marketing, Vol. 34 Iss: 5, pp.670 - 689.

R.A. Powell - H.M. Single - K.R. Lloyd (1996), "Focus groups in mental health research: enhancing the validity of user and provider questionnaires", International Journal of Social Psychology 42 (3), pp. 193-206.

R. Prabhakar (2014), "What are public attitudes towards financial capability? Evidence from focus groups in London", Policy Studies, Vol. 35, pp. 131-146.

J. Prescott - J. Bogg (2011), "Segregation in a male dominated industry: Women working in the computer games industry", International Journal of Gender, Science and Technology, 3 (2011), pp. 205-227.

A. Rajna-W.P. SEzat. - S.A. Junid - H. Moshiri (2011), "Financial Management Attitude and Practice among the Medical Practitioners in Public and Private Medical Service in Malaysia", International Journal of Business and Management, 6(8), pp.105-113.

D. B. Rao (2004), Scientific Attitude, Scientific Aptitude and Achievement, New Delhi: Discovery Publishing House.

D. W. Stewart- P. N. Shamdasani (1990), Focus groups, Theory and practice, Sage, Newbury Park (CA).

R.J. Sternberg - W.M. Williams (1996), How to develop student creativity, Alexandria, VA: Association for Supervision and Curriculum Development.

N. F.Tahar- Z. Ismail - N. D.Zamani-N. Adnan (2010), Studentsee Attitude Toward Mathematics: The Use of Factor Analysis in Determining the Criteria. Procedia-Social and Behavioral Sciences, 8, 476-481.

S. Wilkinson (1999), "Focus groups a feminist method", Psychology of Women Quarterly, 23, pp. 221-224.

World Economic Forum (2010), The Global Gender Gap Report 2010. 
Appendix 1 -Images for "Finance" presented during the focus group sessions

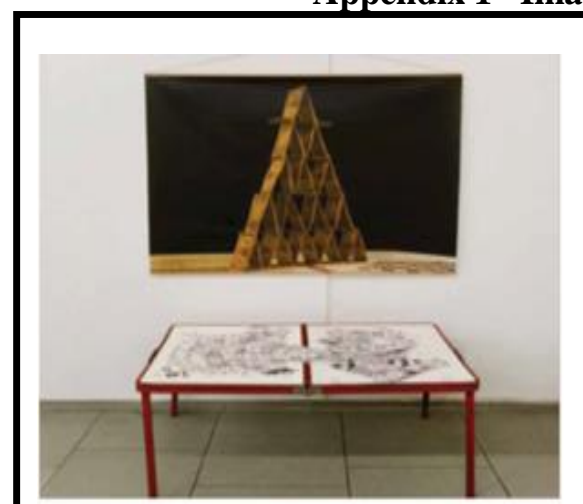

House of Cards

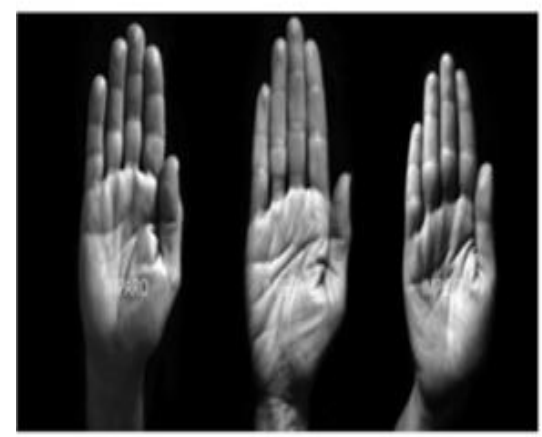

Learning, commitment, employment Ltd.

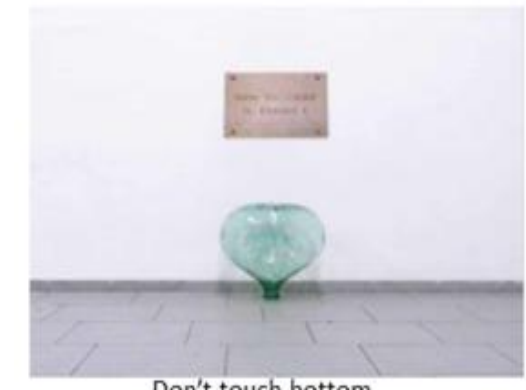

Don't touch bottom

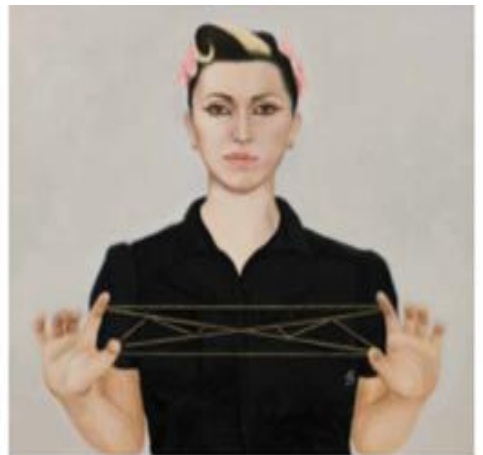

Strategies

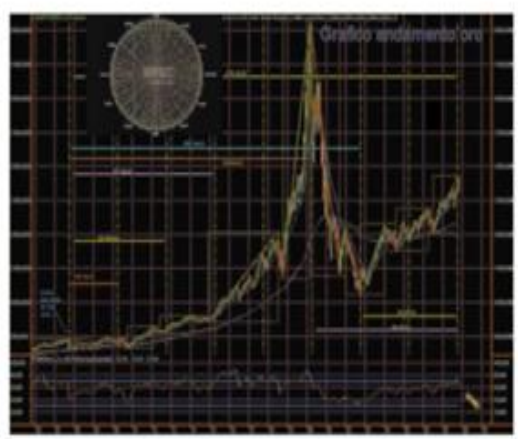

Dance if you like

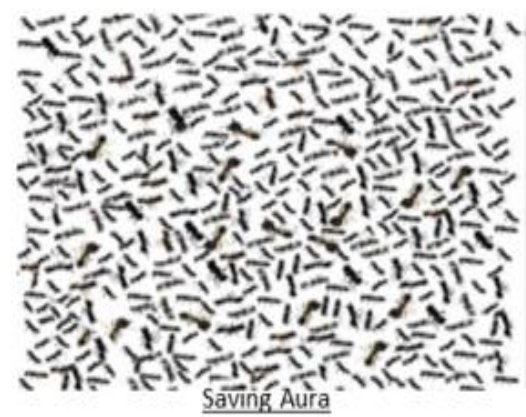

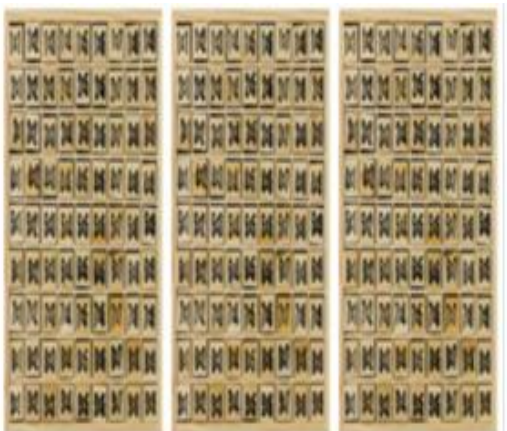

Calculation

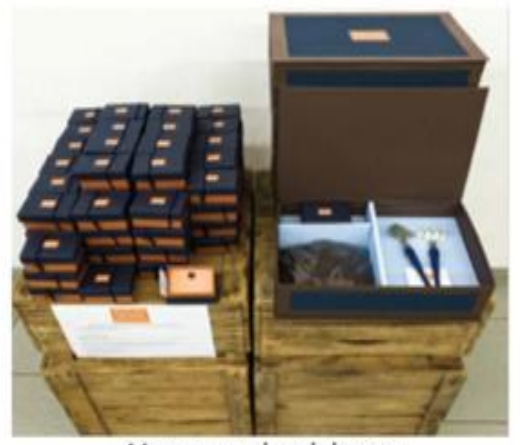

Money, seed and dreams

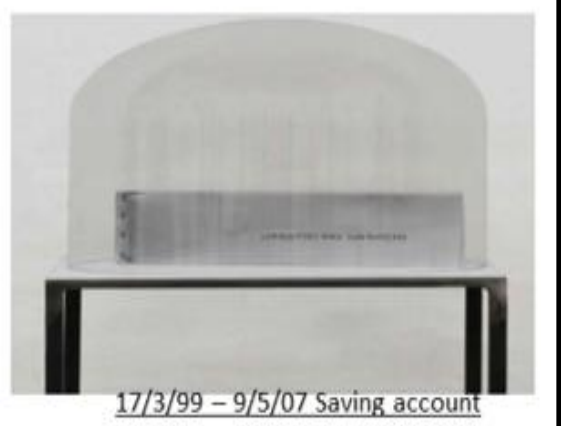

Source:AssogestioniandAccademiadelle Belle Arti di Brera (2011). 